\title{
"Should I Stay, or Should I Go?": The Experiences of, and Choices Available to Women of South Asian Heritage Living in the UK When Leaving a Relationship of Choice Following Intimate Partner Violence (IPV)
}

\author{
Kalwinder K. Sandhu and Hazel R. Barrett * \\ Centre for Trust, Peace and Social Relations, Coventry University, IV5, Innovation Village, Cheetah Road, \\ Coventry, West Midlands CV1 2TL, UK; ab6745@coventry.ac.uk \\ * Correspondence: h.barrett@coventry.ac.uk; Tel.: +44-797-498-4093
}

Received: 31 July 2020; Accepted: 25 August 2020; Published: 3 September 2020

\begin{abstract}
Researching South Asian women who have departed social norms and married outside the social conventions of their culture widens our understanding and knowledge on the topic of Intimate Partner Violence (IPV). This paper will investigate how the women participating in the research navigated the socialisation of arranged marriage and expectations on them as women, and how this influenced their decisions to remain in violent and abusive relationships. Often without family support or the "safety net" of an arranged marriage, the women stayed in abusive relationships longer than they would have done if the marriage had been arranged. The findings show that the women's experiences of leaving the relationship are mediated by the context of forming an intimate relationship. A qualitative research approach using Black Feminist Standpoint Epistemology employed thematic analysis to give voice to South Asian women's experiences and insights into their experiences of, and responses to, leaving abusive relationships. The analysis shows that women's agentic act of choosing a partner became the very barrier to leaving the relationship if it turned violent and abusive.
\end{abstract}

Keywords: women of South Asian heritage; intimate partner violence (IPV); choosing own partner; UK; leaving an intimate relationship

\section{Introduction}

There are many pretexts surrounding why women remain in abusive relationships, including lack of financial resources and support networks, fear of further violence, and religious beliefs (Collins 2000; Eckstein 2011). South Asian women living in the UK face additional barriers that may prevent them from leaving violent and abusive relationships, including bringing shame on the family (Siddiqui 2013), and their insecure immigration status (Anitha and Gill 2011). South Asian women's experiences of domestic violence include forced marriage and honour-based violence (Gill and Hamed 2016; Siddiqui 2013). Perpetrators of domestic violence can be their family members carrying out honour-based violence (Gill and Harvey 2017; Siddiqui 2011) as well as domestic abuse from their intimate partner (Gill 2004). Social constructs of honour and shame are used to coerce and force many South Asian women into marriage and to remain within such marriages (Sen 2005). Women's transgressions of such codes can become the legitimising avenue for violence (Gill 2003). Feminists have charted examples where family honour is considered to be violated and brought the family into disrepute (Anitha and Gill 2011; Gill and Brah 2014; Siddiqui 2013): pregnancy outside of marriage (Meetoo and Mirza 2007, p. 187) or choosing an intimate partner (Siddiqui 2005). For some South Asian women, choosing a 
partner outside the social conventions of arranged marriage can be a potential arena of abuse and violence (Amos and Parmar 1984; Anitha and Gill 2009; Dustin and Phillips 2008; Gill and Harrison 2019; Siddiqui 2013).

The aim of this paper is to critically examine South Asian women's experiences of leaving a violent relationship in the UK where they had chosen their partner, with and without the support of their families. Using a Black Feminist lens, the research explored the lived experiences of these women in transgressing the cultural norms of arranged marriage and, in particular, critically investigating their negotiations in responding to the consequences they faced in leaving an abusive intimate relationship that they themselves had chosen. The analysis shows that the agentic act of choosing an intimate partner became the very barrier to leaving the relationship if it turned violent and abusive. By researching South Asian women who have departed social norms and married outside the social conventions of their culture, the research widens our understanding and knowledge on the topic of Intimate Partner Violence (IPV). The research examined the experiences of these women with respect to the way an intimate relationship was formed outside of arranged and forced marriage, and how this decision had a huge bearing on the process the women went through to leave the relationship when it became abusive. This research investigated how the women participating in the study navigated the socialisation of arranged marriage and expectations on them as women, and how this influenced their decisions to remain in, or leave, the violent and abusive relationship. It demonstrates that the women's experiences of leaving the relationship are mediated by the context of forming an intimate relationship, and shows that their autonomous decisions to form the relationship can become the very barrier to leaving the relationship. The voices of the women participants reflect the complex processes and negotiations that this cohort of women engaged in when leaving abusive partners. These were partners they chose, whether they acted against the wishes and norms of their family and culture or with their family's full support.

\section{Forming Intimate Relationships}

There are three main factors pertinent to marriage for women of South Asian heritage living in the UK. The first considers how women are socialised into marriage and specifically-arranged marriages. It highlights the fluid nature of arranged marriage, with the exception of one fixed entity, namely that of parents' involvement in the choice of partner. The second relates to how notions of honour and shame are gendered and thus shape expectations and conformity of women's behaviour. Honour and shame are some of the ways in which patriarchy control and power, the third factor, subjugate women when entering and leaving a marriage.

\subsection{The Practice of Arranged Marriage in the UK}

Dominant discourses construct the South Asian woman as a good wife and mother (Kallivayalil 2010), thus socialising women to value success in relationships at all costs can be a form of coercion (Anitha and Gill 2009). Scholars have highlighted the contrast between the individualistic notion of choosing one's own marriage partner and the family-based system of influence (Pande 2015; Zaidi and Shuraydi 2002). Family-based systems include "arranged marriages" as a way of affirming an intimate relationship and this form of marriage is practiced by many diasporic communities in the UK including Middle Eastern, Turkish, African, Chinese, Japanese, and Jewish communities as well as those of South Asian heritage (Siddiqui 2003; Zaidi and Shuraydi 2002). Arranged marriage can serve a societal objective to secure and preserve status within the family, kinship, and communities, and thus is "a key instrument for economic, social, and political stability in South Asian communities" (Bhopal 2011, p. 434). Partners are selected on the basis of caste, religion, family wealth, and status (Bhopal 2011). Parents or other family members take the lead role of administering and mediating the process and where and when prospective partners can be encouraged to meet each other.

Arranged marriage, along with many social norms, is not a fixed convention; it evolves and changes (Pande 2015; Siddiqui 2003). In her study of women of the Indian diaspora, (Bhopal 2011) 
found women negotiate and exercise "varying degrees of choice" of partner whilst still meeting criteria of wealth and social status (Bhopal 2011). Gill and Harvey (2017) studied young British South Asian's attitudes and responses to arranged marriage, including the right to marry or not, and found that they arranged meetings between several prospective partners and parents, and then, in consultation with their parents, decided on the most suitable partner. Romantic love and arranged marriage are overlaid through the use of technology, where South Asian young people use internet dating to assess the suitability of a partner against criteria of race, religion, and social status (Chantler 2014).

The single fixed convention within the fluidity and evolving nature of arranged marriage is that of the involvement of parents or family members in the decision-making process in the choice of partner. In her study of British Indians' practices of arranged marriage, (Pande 2016, p. 391) points out the "significant choice allowed to them by their parents and family members". The word "allowed" is noteworthy. It exemplifies the power held by parents (and other family members) in not only the final decision of choice of partner, but also the amount of choice they sanction for their children. The significant role played by the family explains why an arranged marriage can provide a safeguard of family protection if a woman faces difficulties in the relationship (Mohee 2011). Women who have stepped outside social norms of arranged marriage and autonomously formed an intimate relationship of choice may not have this family safeguard.

\subsection{Honour and Shame}

Such protection by family members can represent women's socialisation and expectations of their own role as wife, mother and daughter. Gender-role expectations on women emphasise that the primary roles are to be a good wife and mother; in essence, women's socialisation of marriage (Kallivayalil 2010). For example, ensuring that successful careers outside the home do not upset the balance of power within the home between husband and wife (Oakley 2016). South Asian women can experience the (im)balance of power within the family and community as well as between the two partners (Patel 2003a).

Gendered socialisation is associated with the gendered nature of domestic violence such that "cultural traditions have always oppressed women while liberating men" (Patel 2003b, p. 249). Men are the decision-makers and protectors of the values that communities hold, whereas women "face very real consequences if they find themselves transgressing the norms of their community, whatever the reason" (Patel 2003b, p. 249). The importance of understanding the balance of power within a marriage, and in the community, is the way in which that power is manifested through the specific forms of socialisation called "honour" and "shame" (Patel 2003a).

Social constructs of honour encompass expectations of behavour of family integrity, respect and pride, and transgressions of these expected traits of behaviour can bring shame on the family (Gill and Brah 2014; Toor 2009). Acts of behaviour that constitute dishonour include choosing an intimate partner for oneself (Sen 2005). Mitigating the consequences of honour can lead to dire consequences for women (Gill and Brah 2014; Sen 2005; Siddiqui 2013) such as forced marriage, ostracism from their family and community (Sen 2005), and even death (Siddiqui 2011). South Asian women's socialisation of behaviour according to family honour is thus relevant to women who have stepped outside social norms as they have not maintained the status quo and performed their expected roles within the community.

\subsection{Patriarchy}

Women's duty to serve the collective forms part of defending and maintaining patriarchy and gender inequality. A study conducted by (Gill and Harvey 2017) found that women were pressurised to conform to socially constructed traits of femininity, including putting the family's interests above their own. Women's experiences of violence occur "in a cultural context and that differences of culture should not lead to a denial of civil rights" (Patel 2003a, p. 176). 
Human rights are enshrined in marriage within article 16 of the Universal Declaration of Human Rights, "Men and women ... are entitled to equal rights as to marriage, during marriage and at its dissolution" (United Nations 1948, p. 4). It follows that such rights are preserved in all intimate relationships and by the same token, the ability to leave a relationship. Feminists situate South Asian women's experiences of domestic violence within the context of gender inequality and thus human rights, and not as manifestations of culture or religion (Patel 2013; Siddiqui 2014, 2016).

South Asian women's specific experiences within patriarchal and structural constraints of marriage, divorce, and intimate relationships can be contested areas within families where patriarchal control and power determine the position of women, privilege men's status, and enforce control over women's bodies and lives (Anitha and Gill 2009; Wilson 2006). Patriarchy subjugates women in different ways and so the experience of oppression differs amongst women (Lorde 1996), and the historical and present context of race and class oppression faced by ethnic minority women is crucial to understanding how power relations work to subjugate women (Amos and Parmar 1984).

Patriarchal practices are not wholly a binary notion in which women either comply or do not. Women may negotiate "trade-offs" to protect their own interests, for example, choosing financial security that their partner provides for themselves and their children over leaving the relationship and plunging into poverty (Walby 1990). Some feminist scholars have argued that this recognition of negotiation is not attributed to all populations of women. Western liberal feminists, for example, have not always recognised how women of other cultures also negotiate everyday patriarchy within the limits and constraints they experience. It is crucial to recognise this negotiation and agency, and avoid portraying women from certain cultures as being wholly "prisoners" or "dupes" of patriarchy (Narayan 2001, p. 418).

Patriarchal forces and gendered social norms provide the backdrop for the complex and varied ways South Asian women may exercise agency and negotiation in the process of leaving abusive relationships. Such understandings are important to show the need for a conceptual framework that explicates South Asian women's lived experiences at the intersection of gender, ethnicity, age, socio-economic status, and other inequalities, in order to gain a deeper understanding of women's experiences of gendered socialisation of honour and shame and how power relations influence their agency in forming intimate relationships.

The three factors presented here are relevant and closely linked to women of South Asian heritage living in the UK, who choose their own intimate partners. By choosing their intimate partners, the South Asian women in this study appear to be transgressing such gendered norms. Their subsequent experiences of intimate partner violence within the relationship brings to the fore the consequences of their decisions where the act of choosing a partner becomes the barrier to leaving the abusive relationship. This paradox has received little attention within scholarship on intimate partner violence and specifically why women choose to remain or leave a violent and abusive relationship.

\section{Research Design, Methodology and Methods}

It is the knowledge gained from experiences of subjugation due to gender, age, sexuality and race that evokes critical social theory pertaining to black women. Social theories by Black Feminists reflect women's views of their lived experiences of multiple intersecting axes of oppression. Black Feminism incorporates knowledge and analysis of the ways in which structural power not only oppresses women, but also how different groups of black women are oppressed in different ways. Black Feminist Thought, as a "critical" social theory, underpins the development of "more specialized knowledge" that captures the contradictions of dominant ideologies and the lived experiences of black women (Collins 2000, p. 12). Examining women's experiences within the context of the social world they occupy, not only leads to an understanding of the power base that enforces structural inequalities on women's lives, but also an understanding of women's actions (Collins 2019). Black Feminism conceptualises the gendered structures of power and so informs the context of women's agency, but also elucidates the reasons for their actions. 
A central tenet of this research is to give voice to South Asian women's experiences and thus to understand their social world. The core of Black Feminist Standpoint epistemology has been to make visible previously erased Black women's narratives and place them on a par with Black men's and White women's narratives of oppression (Cho et al. 2013). Black Feminism was employed as the qualitative research approach, to give voice to South Asian women's experiences and provide an insight into the workings of gendered control and power when women are going through the process of leaving a violent and abusive relationship in the UK (Collins 2015; Gill 2004; Siddiqui 2016). Black Feminism pursues knowledge that emphasises the importance of understanding the context of women's lives, that is reflexive in approach "so that the scope, complexities and diversity of black women's lives can be successfully captured" (Reynolds 2002, p. 604). The centring of South Asian women's lives and theorising through the multiple social locations of ethnic identity, gender, age and socio-economic status offers new knowledge. This knowledge is not only of experiences of intimate partner abuse and familial violence, but also in conjunction with the understandings of the complexities behind decisions on whether to leave the abusive relationship or not. Thus Black Feminist Standpoint lends itself to the "angle of vision" (Collins 2000, p. 12) through which South Asian women see and live their world, from their perspectives, arising from their lived experiences of transgressing social norms by choosing their own intimate partner and of intimate partner and familial violence.

The empirical data presented in this paper were collected as part of a PhD research project that examined the lived experiences of South Asian women living in the UK who "choose" their intimate partners and explored their responses to familial and intimate partner violence. The data collection was undertaken in 2016 and at the time of the research, all participants lived in the UK. All the women had grown up with social norms of marriage that included arranged marriage, and all had transgressed such cultural practices to form an intimate relationship with a partner who was then violent and abusive in that relationship. In addition, some women also experienced familial violence.

After receiving ethical approval, participants were recruited through a mixture of using Facebook and professional networks. The Facebook posting included details of the research project with an emphasis on confidentiality and anonymity. Participants were asked to use the direct message functionality to get in touch if they wished to engage with the research. Six participants were recruited this way. In total fifteen participants were recruited in four different ways. Figure 1 shows the breakdown.

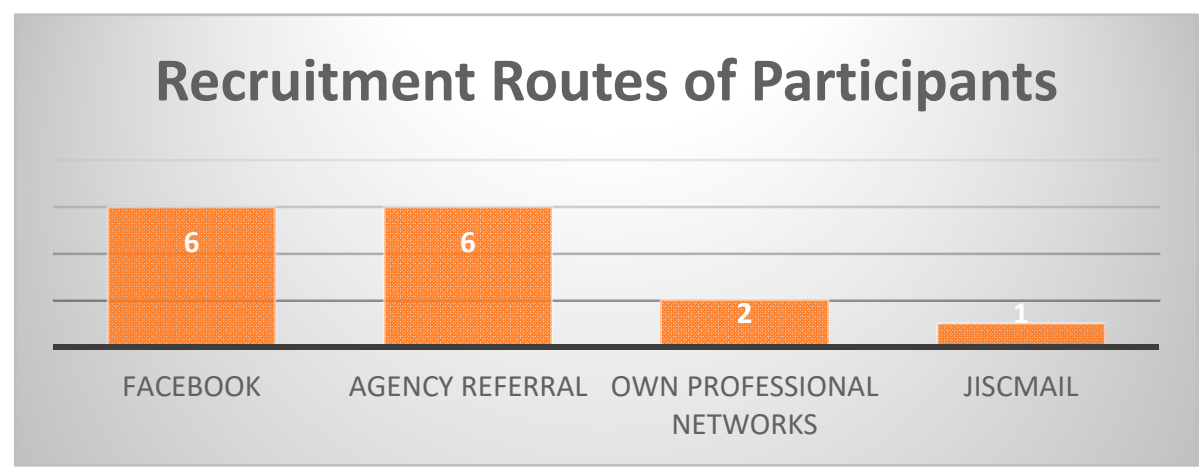

Figure 1. Recruitment routes of research participants.

The initial contact was followed up with a phone call to the participant to give more details concerning the research, the method of data collection and to emphasise the ethical procedures and reflexive position of the researcher. An informed consent form and participation information sheet were sent to each respondent prior to the interview. Of the fifteen participants interviewed, eleven were interviewed in one-to-one semi-structured interviews and the remaining four were interviewed in a group setting. The interviews were carried out between January and October 2016 and took place in a number of different locations as shown in Figure 2. 


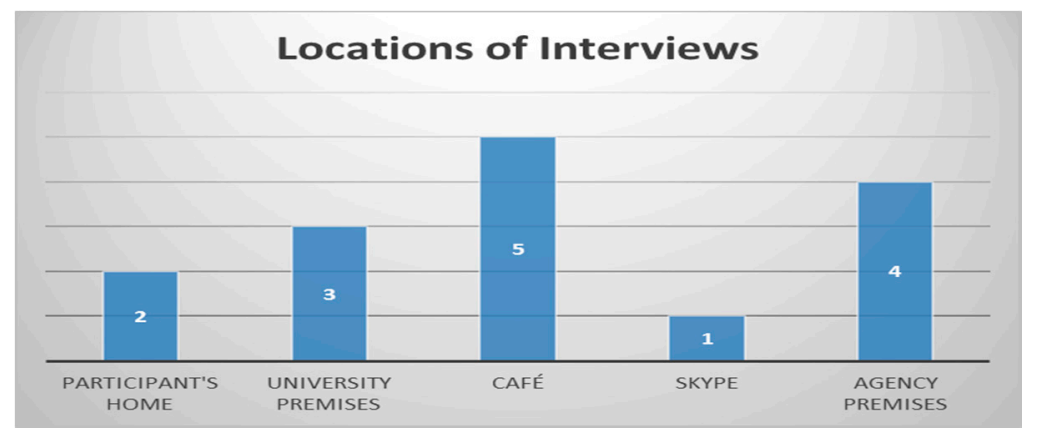

Figure 2. Location of interviews.

Most of the interviews were held in cafes chosen by the participant in the town or city where they lived. The group interview took place in a meeting room in the domestic violence agency's offices, referred to in Figure 2 as "agency premises". Two of the interviews were held in the participant's own homes and university ethical and safety guidelines were followed. On both occasions, the women were alone in their homes during the interview. One interview was held using voice over internet technology, Skype, because the participant lived some distance away and on a number of occasions an interview had been arranged but the participant had to cancel. Using Skype allowed her to cancel at short notice without wasting travelling time.

With the women's permission, all interviews were audio-recorded. They were in control of the audio recording and could switch off the recorder at any time during the interview. The participants' identities were anonymised for their safety. The audio-recordings were transcribed verbatim (Braun and Clarke 2013). The group interview was undertaken in four different languages; Punjabi, Hindi, Urdu and English. The researcher undertaking the group interview was fluent in Punjabi and English but less so in the other two and so an interpreter was commissioned to quality-check the final transcription. To stay true to the balance-of-power relations between researcher and researched (Letherby 2003), and so that the participants could participate in the final transcripts and have control over their content (Kelly 1988), the transcripts were sent to the participants and they were asked to review the content. The transcripts were coded to identify significant subject areas relevant to the research. Thematic analysis was applied. The codes were linked into identifying patterns that reflected themes such as "Relationship with parents" and linked together to produce thematic maps to visualise the codes within a theme and the different levels of themes in order to produce overarching themes with sub-themes under them (Braun and Clarke 2013). Significant themes emerged illustrating the complexity of women's experiences of forming intimate relationships and their decisions to stay or leave the relationships.

The ages of the participants at the time of the interviews ranged from twenty-three to fifty-seven years. Eight of the women were of Indian heritage, six of Pakistani heritage, and one of mixed Asian and African heritage. Of the eight women of Indian heritage, four were of the Sikh faith, two were Hindu, one was Christian, and one was Buddhist. Four of the women of Pakistani heritage were Muslim, one was of no faith, and one was an anti-theist ${ }^{1}$. The participant of mixed Asian and African heritage was Muslim.

The fifteen women had twenty-two children between them; three women had three children, six women had two children, one woman had one child and five women had no children from the relationships. One woman had an abortion, forced on her by her family.

The longest period a woman remained in her intimate relationship was twenty-five years, and the shortest time was nine months. Nine women were in relationships for five years or less. Five women experienced two abusive intimate relationships. Ten women had experienced both intimate partner 
violence and familial violence, which is domestic violence from parents, siblings, or extended family members. Five women participants at the time of the research were still estranged from their families on account of choosing their own partners.

The experiences of the researcher at the intersections of gender, class and ethnicity have "bearings upon the relationship between the researcher and the researched" (Bhopal 2000, p. 73). The positionality of the researcher undertaking the fieldwork, as a gendered, racialised South Asian woman researcher, researching other South Asian women, was central to giving voice to women who otherwise may not be heard. Although the participants and the researcher shared South Asian heritage, there were differences in socio-economic, religious and cultural backgrounds, with differing immigration and British residency status. This reflected the heterogeneous, complex social and political positions we occupy, as researcher and research participants and as South Asian women in the UK today. At the same time, as a Black Feminist researcher researching intimate partner violence, the lead author found the shared gender, and racial identity led participants to reveal very intimate and traumatic experiences because of her experiences as a situated knower (Collins 2000).

\section{Results}

This section presents the results of the qualitative data collection. All of the women who participated in the research said that they had chosen their own partners and all had experienced intimate partner violence within their personal relationships. Only two had remained with their partners. All participants experienced complex negotiation and difficulties in leaving their partners; rooted in their decision to choose their partners and their fear of the consequences of their decisions. Three themes emerged from the thematic analysis of the interview transcripts. These were women's sense of personal responsibility in choosing their partners; women stayed in relationships longer due to going against social norms; and their relationship with their parents. The themes highlight the many different barriers to leaving the relationship faced by these women. The women carried the "burden" of choosing their partners, which manifested when they looked to leave the abusive relationships. Women also stayed in the relationships longer because of this weight they carried. Women placed huge emotional investment in their relationship with their families, in particular their parents, whether their relationships had broken down with their parents or not. Each of these themes are explored in more detail below:

\subsection{Women's Sense of Personal Responsibility in Choosing Their Partners}

All research participants expressed a sense of a "burden" they were carrying because of their decision to marry or to be in a long-term relationship with a partner of their choice. This was a decision in conflict with the cultural expectations and norms of their family and community. Jazmin, a 24-year-old British born Muslim woman of Pakistani heritage who was in a long-term relationship with a Muslim man of Iranian descent, blamed herself for her decision and she blamed her partner for the breakdown of her relationship with her family.

"Oh, it's like my fault because I chose him, and I wanted to be with him and cos of him I've been disowned" -Jazmin

Nirvair, a 29-year-old British born Sikh woman who married her husband, a Sikh Indian national, with her family's full support referred to the implications of the fact that the decision to marry her husband was hers solely.

"It was me who went to them [her parents] and said, "I want to marry him". It wasn't them saying "You have to marry him" and I think for me personally it did. It was quite a big influence on everything." -Nirvair

Women participants also spoke about how they alone had to resolve the situation because of their decision to choose their intimate partner. Krishna, a 45-year-old Hindu woman with two children, felt it was her responsibility to resolve the situation with her abusive husband. 
"I chose it. I'm the one who, who got myself into this and it's my job to put up with it not everybody else's job to get me out." -Krishna

All the women expressed a huge sense of responsibility. This reflects an understanding of the wider implications they faced as a result of transgressing the social norm of arranged marriage and choosing their own partner. The women blamed themselves. They felt they would be judged and they had to resolve the situation without asking for any help from their families or others. The family did not play any role in choice of partner and so the women, now facing difficulties, did not feel they had the right to ask for protection (Mohee 2011).

\subsection{Women Stayed in Relationships Longer}

Choosing their own partners was a significant factor in understanding the consequences and deciding on whether to leave the partner they had chosen. Many women described how they stayed in abusive relationships longer than they wanted to and made special efforts to make the relationship work. Some women felt judged by society, felt that they were in the "wrong" and the fear of judgement led them to place importance on staying in their relationship over their own safety. Harjit is a 57-year-old British born Sikh woman who married a Sikh man. Harjit talked about her concerns about the personal costs of her decision to leave him. Harjit explains:

“... so, part of me thought "No I've got to stick it out and prove that I was right" or I won't be able to deal with erm, almost that, that personal shame of I went through all of that, did that, put my family through that and now I end up with this." - - Harjit

Other women felt that by choosing their partner themselves they had created the situation they found themselves in and so had to continue enduring the abuse from their partners. Their efforts to make the relationship work had the opposite effect. Jazmin stated

"I thought I can't [leave the relationship], I have to make it work so it's like that saying that they say, "you make your own bed, you lie in it" (laughs). So that's what I tried to do but it-the situation got way out of hand." -Jazmin

Sara, a 36-year-old British born Muslim woman who was in a relationship with a man of Black Caribbean heritage also spoke about why she endured her partner's violence towards her.

"I chose to be with him and now I'm in this situation. I have to put up with it. I have to try and make it work." - Sara

Women endured emotional, financial and physiological abuse as well as physical violence because they regarded their decision to choose their partner outweighed everything else. They reflected on their actions and accountability.

"I think choosing my own partner... made me feel like I had a responsibility to make that marriage work... I think if he didn't physically abuse me, I think I would have stuck it out ... I tolerated it cos I just thought "You know you made the decision to be here" ... and I think that influenced a lot of my poorly judged decisions at the time" - Nirvair

Most of the participants endured one abusive intimate partner relationship. Four women experienced two such relationships where their first intimate relationships were forced marriages and then chose their own partners in the subsequent relationship. Two women experienced intimate partner violence in two relationships, where the perpetrators were partners they had chosen. This factor became significant, especially in the second relationship. Krishna explains.

"I felt ashamed of myself and especially when it happened second time, that's even worse you feel because then that's the reason I put up with it for eight years because I thought people won't believe me, again. "The story repeats again" that's what I said and now I joke around, and I said "You know what "One time wasn't enough, so I had to dive into a big sea again to feel the water" -Krishna 
Women stayed in the relationships longer to prove to their families and communities that their decisions were correct despite their departure from the social norm of arranged marriage. They put energy into making the relationships work because they did not want to be judged by society a second time for rejecting expectations of them to remain in the relationship. The women's accounts show the depth and influence of valuing success in relationships at all costs (Anitha and Gill 2009). The women's sense of honour and shame enforced such pressures to remain in the relationships at all costs (Siddiqui 2013). The gendered expectations and influence of honour and shame on women who have chosen their intimate partners, when negotiating whether to leave the abusive relationship are hitherto rarely explored within the academy.

\subsection{Relationship with Parents}

An emerging theme centred on how the women's relationships with their families fared as a result of their rejection of social norms to be in an intimate relationship with a person of their choice. All the women participants talked about the significance of their relationships with their families. The parents of six women were supportive throughout. Parental relationships broke down for the remaining nine, and of these four women were still isolated from their parents at the time of the fieldwork. Their relationships with their parents and siblings were important to them, the bond they had with their families and the personal costs of strong ties with families being severed because of their decision to be in an intimate relationship with a person of their own choosing was devastating to them. Harjit referred to the fear that her family would spurn her on finding out her relationship had broken down.

"I certainly was erm, almost afraid of a second rejection if that makes sense, in that was I going to be told "Well, you know, you're the one who made that decision? You're the one who erm, decided it". or whatever and I certainly missed being able to share what was going on, but I didn't feel that I could for fear of being told "well, no it was your decision" - Harjit

The close ties of family relationships also manifested in women's reflections of disclosing the abuse to their parents. Samia expressed how momentous an occasion it was:

"I think it was actually one of the hardest things was to tell my mother what had been happening because I had, I'd chosen him" - Samia

Samia felt the size and the gender of her family members factored into how she weighed up the risks and consequences of choosing her partner and the consequences of how many family members she had to tell.

“... I mean for me in a way I only had my mother with whom I wasn't getting on. I had no other family really. I had nothing. All I had was rubbish. I mean I don't mean that-it's just bad you know and to lose my mother was erm was bad ... but I've talked to other women who are in similar situation and they couldn't make the choices" - Samia

In addition to the size of the family, women found their mothers and fathers responded differently. Pania, a 31-year-old Muslim woman of African and Indian heritage with two children aged 3 and 4 years said.

"So, I do speak to my mum and she's really humble, really. She's forgiven me. She's, she's okay and I'm quite relieved but my father, no, no, no, no for him ... still my father is, I think, is very angry ... He (Pania's father) says to him[self] I'm a dead person. He doesn't wanna know anything about me ... It's like I've killed everything in him," -Pania

Some women felt a sense of betrayal and were angry at their parents' lack of support and the subsequent isolation they felt from their families. As their offspring, women felt they deserved support. Kiran describes how she regarded her parents' response to her situation and her expectations of them: 
"My parents may not have wanted to support me but to completely remove contact? ... my situation was so bad, it's because of that, that I left and thought they would come round. My husband was hitting me, and it wasn't that they came and cried that their daughter is being treated so badly. Support is about "this is my daughter. She's our blood and we'll care for her and help. So, she made a mistake, never mind." But no "she made a mistake so leave her. She made a mistake, leave her." That's what they said to me. The whole blame is on me." -Kiran

Women also experienced isolation from their wider community. Krishna describes the comments people made when she attended local community events after splitting up from her husband.

"I was blacklisted in the whole Indian community. No one would talk to me. I was a bad person and they'll start saying in the public places... "Do you know what if you want to kick your mother-in-law out and your husband out ... come over because ... she will give people training" and err I thought that was horrible of Indian community not understanding you. What woman is going through deep down" -Krishna

As well as the community, partners also exploited women's isolation and estrangement from their families further entrenching women's sense of being completely alone. Sara gave an example of the verbal abuse she received from her partner, which became a factor in her staying in the relationship longer.

"“Your family didn't care about you. They didn't support you." Basically, I had to put up with whatever was thrown at me ... It was my choice, I did this. I chose to be with him and now I'm in this situation. I have to put up with it. I have to try and make it work." - Sara

Not all of the participants' relationships with their parents had deteriorated. Some women described the emotional support and response they received from their parents. Renaisha is a 38-year-old woman of Indian heritage who has two children aged 14 and 12. She described her parents' response to her when she told them about the domestic violence she had suffered for 17 years.

“... my parents didn't know for seventeen years but when they realised they were extremely supportive. "No, you don't deserve a life like this. You need to leave ... This is not a marriage. This is not what marriage is." ... Amazingly, (starts crying) I think that the first thing I, I was expecting to hear from my mum and dad that "we had told you" and I was shocked and to this day they have never mentioned it." - Renaisha

Renaisha was not expecting the reaction she received from her parents. Other women such as Krishna and Anita received mixed messages from their parents and overall found their parents to be supportive:

"I cried so much to my mom over the phone and I said "Mom, I don't know what to do." I didn't go into details with my mom. I said, "Mom I can't live in this abuse anymore" and my mom goes "I told you not to go." She said "It doesn't matter I'm still here for you, we're all here for you. Why did you put up with it second time? We told you not to put up with any abuses" -Krishna

Others simply did not want to offer an opportunity for their parents to add to abuse their partners. Anita, a 31-year-old woman of Pakistani heritage explained.

"I never told my parents about that relationship because erm it was-there was nothing in that relationship worth telling my parents for ... actually the last thing you want is someone to sit there and slag off your partner to you" - Anita

Parental involvement regardless of level of participation remains significant within the arranged marriage practice (Pande 2015). The women in this study did not involve their parents in their decision-making. However, the women's responses show that both they and their parents are socialised in the practice of arranged marriage and both are negotiating changes to this cultural norm as a 
consequence of the women choosing their own partners. The power imbalances within families remain, illustrated by the way women expected their parents to behave, wanted them to behave, or were surprised by their responses. There is a gap in the literature that looks at the relationship between women and their parents when women have chosen their own partners and their subsequent experiences of domestic abuse within the intimate relationship.

\section{Discussion-“Should I Stay, or Should I Go?"-Barriers to Leaving}

Black Feminism provides the lens to understand and analyse the complexity of South Asian women's decision making when faced with a violent intimate relationship when they have chosen their own intimate partners. It is through the centring of women's voices and deconstructing their responses that an understanding of the context of their lives comes about (Cho et al. 2013). The angle of vision spotlights the lack of protection the women experience from families and face ostracism and isolation as a consequence of transgressing the cultural norm of arranged marriage (Bano 2010; Siddiqui 2016; Thiara 2013). Black feminists have highlighted the cultural and gendered contexts of honour and shame that situate South Asian women's experiences of both familial and intimate partner violence as violations of human rights (Patel 2013; Siddiqui 2014, 2016).

The women's responses suggest that the agentic act of choosing a partner became the key influencing factor in their decisions whether to remain or leave the violent and abusive intimate relationship. Women referred to having to "prove" to their families they had made the "right" decision and could make the "right" decision by enduring many more years of the abusive relationship than they would have done in a relationship approved and sanctioned by their family. Their agency in forming the intimate relationship became the very barrier to exercising agency to leave the violent relationship; a paradox. An arranged marriage would have been seen as a collaborative decision with responsibilities shared between the woman and her family and with familial support if the relationship faltered (Gill and Harvey 2017, p. 85). In her study of South Asian Muslim women negotiating marriage and their identities, (Mohee 2011) found that some women did not choose their own partners because they would lose the protection of their families if those marriages did not work out and also they could not attach blame to their parents. In contrast, the women in this study did not have this "safety net" because their intimate relationships were not a collaborative family decision but an individual choice. The connection between family support and arranged marriage shows how the barrier to leaving the violent relationship comes about and how women's vulnerability stems from not having complied with social norms.

The women remained in relationships for longer periods in order to try to convince themselves and their families that they were originally justified in forming the intimate relationship of choice and thus transgress the cultural norms of arranged marriage. Fearing a second rejection, staying in the relationship longer, and fearing judgement from the community and family, all point to a desire to prevent further experiences of conflict with the family, stemming from pressures to maintain patriarchy through the gendered nature of dishonour and shame. Thus demonstrating the pressure women continued to feel to conform to social constructs of honour and shame despite transgressing social practice of arranged marriage; another paradox.

The women themselves considered their agentic act of choosing their own partners as one of transgression. They could not separate out the act of choosing a partner from the socialisation of arranged marriage and associated honour and shame. Having chosen their partners they continued to be enmeshed in the sense of dishonour and shame they had brought onto their family as a result of their rejection of cultural norms concerning intimate relationships (Sen 2005). Furthermore, the breakdown of the relationships gave credence to the belief that choosing partners outside of arranged marriage is flawed. Such violation of patriarchal power in turn gave legitimacy to the domestic violence against them by both their families and their partners (Siddiqui 2013). The belief systems are so entrenched that the women, despite being victims, punish and blame themselves for the domestic abuse they experienced (Kelly 1988). Thus, the threats of losing respectability in the community (Siddiqui 2013) 
and being ostracised from the family (Bano 2010) are just as powerful when leaving a relationship, especially an abusive one, as when forming it.

The women chose their partners amidst power imbalances within their families. Power relations within the family, including parents, siblings, and extended family members, and community pressure can leave women vulnerable and with no or little power as agentic subjects (Anitha and Gill 2009; Wilson 2006). Harjit's phrase "I went through all of that, did that, put my family through that and now I end up with this" reflects multiple, complex and contradictory layers of agency and negotiation of cultural norms (Anitha and Gill 2009; Wilson 2006). Such differential power portrays how women can perceive a mother's power over them as well as that of their partners (Yuval-Davis 2011). Women's responses to power varied depending on whether their mothers or intimate partners were exercising power over them. They applied a differential factor; they were still beholden to their mothers in a way they were not to their partners. A socially constructed trait of expected behaviour on women is to put their family's interests above their own (Gill and Harvey 2017). Fear of rejection from a mother was greater than from a partner.

Women participants recognised that only having women members of the family to answer to was safer than where there were both men and women family members. Patriarchal control and power determine the status of women, privilege men's status, and enforce control over women's lives (Anitha and Gill 2009; Wilson 2006). This can also be extended to the women's expectations towards their fathers as the patriarchal head of the family-an internalisation of gendered norms. Such gendered differences amongst parents reflect power imbalances between mothers and fathers and the expected gendered norms of marriage (Patel 2003b). Fathers, as patriarchs, are conduits of those expectations and have the power to decide who, and who is not, part of the family. By ostracising and isolating their daughters, as though they never existed and had no right to be part of the family because of shame they had brought on the family, fathers redeem honour in the community (Sen 2005). The ultimate consequence for a daughter and the show of power by the father is to cut the daughter off from her family.

The conformity to socially constructed traits of gender meant that Harjit put her family's interests above her own, in the negotiation to leave the abusive relationship (Gill and Harvey 2017). Harjit's choice of partner was both inside and outside culturally expected norms. Marrying someone of the same religious and cultural background placed her within cultural and gendered expectations. However, marrying someone outside of the arranged marriage practice and in extreme public defiance of her mother placed Harjit and her mother outside of cultural and gendered norms. Mothers are held responsible for their daughters' transgressions in the eyes of the community (Bhopal 2011). As well as the acts themselves, it is the public knowledge of such violations of "izzat" that causes families to experience "sharam" and dishonour in the face of the community (Toor 2009). With the community knowing about the women's perceived transgressions and the women's fear of being judged by their community, the women stayed in the relationships longer than they would have had they had an arranged marriage. The women had been judged once already. They remained in the abusive relationship longer because they feared further ostracism, shame, and stigma within the family and community (Thiara 2013) in addition to the ostracism, shame and stigma they were experiencing because they had formed intimate relationships. Control and power over the women extended into the public sphere (the community) as well as the private sphere (family and intimate partner). Women feared shame both within the family and outside of it. The women may have broken social norms by marrying their partners of choice but they were still tied to cultural beliefs of codes of honour and were punished by others (Chakravarti 2005; Coomaraswamy 2005; Siddiqui 2005) and at the same time castigated themselves. Their penalty, along with their admonishment, was to stay in the relationship longer. The women felt they did not deserve the support of their families; but were also resisting social norms, beholden to and influenced by them at the same time (Mahmood 2005).

The women's resilience was realised in surviving the everyday realities of domestic violence from their chosen intimate partner and convincing themselves to remain within the relationship. Leaving 
the relationship (and thereby resisting intimate partner domestic violence) in many cases led to further isolation and abuse from their parents, siblings, and extended family, as well as the intimate partner. Responses to domestic violence and abuse within different relationships and at different times can seem contradictory in nature. The context of women's survival and their negotiation within and in relation to violent relationships is complex (Patel 2003b). Leaving one oppressive relationship can be exploited and lead to further subjugation from a subsequent oppressive relationship. Intimate partner perpetrators can subjugate women, who have left previous violence and abusive familial or intimate partner relationships.

Parental support of women in itself also became a barrier to women disclosing the abuse to their parents. Renaisha stayed in her marriage for 17 years, experiencing domestic violence and abuse, before finally telling her parents. The enforcement of honour carried out by families can be pervasive in nature and result in severe consequences for women (Patel 2003b). The opposite is the redemption of honour, saving women from the "sin" of transgressing social norms where families "forgive" the women and are supportive. This too became a barrier to women leaving the relationship. Renaisha's prolonged hesitancy to disclose the violence she was experiencing to her family illustrates the deep entrenchment of the socialisation of arranged marriage and honour and shame. She feared that by admitting that her relationship was a "failure", she would evidence her poor decision making in the eyes of her family and community.

By choosing their own intimate partners, the women rejected the societal objective to secure and preserve status within the family, kinship, and communities (Bhopal 2011). However, the women were not immune to the social constructs of honour and expectations on them to preserve family honour, respect and pride (Gill and Brah 2014; Toor 2009) even after contravening the social norm of arranged marriage. Faced with consequences such as ostracism from family and community (Gill and Brah 2014; Sen 2005; Siddiqui 2013) they stayed in abusive relationships longer. Women's experiences of patriarchal constraints within families showed how contested the area of intimate relationships are within families to ultimately control women's bodies and lives (Anitha and Gill 2009; Wilson 2006). The result was that the very act of choosing their own intimate partner became the barrier to leaving the abusive relationship. This paper has added to the literature on domestic violence to show how gendered norms and expectations of South Asian women when forming an intimate relationship also apply to when they leave a violent relationship, despite transgressing social norms.

\section{Conclusions}

This paper examined South Asian women's experiences of leaving a violent and abusive intimate relationship where the women had transgressed social norms to form an intimate relationship outside of family sanctioned and arranged marriages. The anonymised participant quotes that have been presented in this paper have been chosen because their narratives demonstrate the complexity of their decision-making and processes of negotiation navigated by the participants to leave their violent relationships. They also highlight the diversity of experiences within the process of leaving the violent relationship, including their responses to family and community pressures. The consequences of choosing their own partners became even more apparent to the women when they experienced intimate partner violence and especially as their families had not been supportive of their choice of intimate partner.

The women added one bad decision on top of another to prove to their families and communities that they were "right" in their choice of partner. They disagreed with the community telling them they were mistaken to choose their partner and they disagreed with the community telling them they were wrong when their relationship was abusive.

Regardless of whether the parents were supportive of the relationship or not, all women in this cohort endured violent relationships to try to make them work. The very act of choosing an intimate partner became the barrier to leaving the relationship, regardless of whether their families were supportive or not. All women stayed in the relationships longer than they wanted to because 
leaving the relationship was to admit to their families and the community that they had been a "failure" and that society was "right" all along.

Gender inequality manifested through cultural notions of honour and shame, together with experiences of power and control, subjugated the women. The complexity of these women's agency reflected the multi-layered responses where women were resisting intimate partner violence and abuse and also responding to gendered norms and expectations from their families and communities. Furthermore, it emerged that partners exploited women's vulnerability and isolation from their immediate family. Their agency in forming the relationship can result in isolation from the family and so they become more susceptible to vulnerability to the intimate partner. Women's socialisation of marriage and specifically arranged marriage situates the women within prescribed notions of gendered norms and behaviour.

Researching South Asian women's experiences of departing social norms and cultural traditions by choosing their own partners widens our understanding and knowledge on the subject of intimate partner violence in general. It shows why women's agency at one point in time may become a barrier to a later act is applicable to other aspects of intimate partner violence. By considering this paradox, researching intimate partner violence informs us of the importance of researching the complexity behind women's decisions to leave or remain in an abusive relationship. What on the surface may be women conforming to social norms requires of us, as researchers, to explore deeper and understand the context of what may seem to be contradictory subsequent actions. Only then can we truly provide the angle of vision that is true to the context of women's lives.

Author Contributions: Conceptualization, K.K.S., analysis, K.K.S., writing, K.K.S. and H.R.B., editing, H.R.B. Both authors have read and agreed to the published version of the manuscript.

Funding: This research received no external funding for the publication of this article.

Acknowledgments: The authors are grateful to Maria do Mar Pereira, whose rigorous review contributed to insightful feedback to this paper.

Conflicts of Interest: The authors declare no conflict of interest.

\section{References}

Amos, Valerie, and Pratibha Parmar. 1984. Challenging Imperial Feminism. Feminist Review 17: 3-19. [CrossRef] Anitha, Sundari, and Aisha K. Gill. 2009. Coercion, consent and the forced marriage debate in the UK. Feminist Legal Studies 17: 165-84. [CrossRef]

Anitha, Sundari, and Aisha K. Gill. 2011. Reconceptualising Consent and Coercion within an Intersectional Understanding of Forced Marriage. Edited by Aisha K. Gill and Sundari Anitha. London: Zed Books, pp. 46-66.

Bano, Samia. 2010. Shariah Councils and the Resolution of Matrimonial Disputes. In Violence against Women in South Asian Communities: Issues for Policy and Practice. Edited by Ravi Thiara and Aisha K. Gill. London: Jessica Kingsley Publishers, pp. 182-210.

Bhopal, Kalwant. 2000. Gender, 'Race' and Power in the Research Process: South Asian Women in East London. Edited by C. Truman, D. M. Mertens and B. Humphries. London: UCL Press, pp. 66-78.

Bhopal, Kalwant. 2011. 'Education makes you have more say in the way your life goes': Indian women and arranged marriages in the United Kingdom. British Journal of Sociology of Education 32: 431-47. [CrossRef]

Braun, Virginia, and Viictoria Clarke. 2013. Successful Qualitative Research: A Practical Guide for Beginners. London: SAGE Publications Ltd.

Chakravarti, Uma. 2005. From Fathers to Husbands: Of Love, Death and Marriage in North India. Edited by Lynn Welchman and Sara Hossain. London: Zed Books, pp. 308-31.

Chantler, Khatidja. 2014. What's Love Got to Do with Marriage. Families, Relationships and Societies 39: 19-33. [CrossRef]

Cho, Sumi, Kimberle Crenshaw, and Leslie McCall. 2013. Toward a Field of Intersectionality Studies: Theory, Applications, and Praxis. Signs: Intersectionality: Theorizing Power, Empowering Theory 38: 785-810. [CrossRef]

Collins, Patricia Hill. 2000. Black Feminist Thought: Knowledge, Consciousness and the Politics of Empowerment, 2 nd ed. London: Routledge. 
Collins, Patricia Hill. 2015. No guarantees: Symposium on Black Feminist Thought. Ethnic and Racial Studies 38: 2349-54. [CrossRef]

Collins, Patricia Hill. 2019. Intersectionality as Critical Social Theory. Durham: Duke University Press.

Coomaraswamy, Radhika. 2005. Preface: Violence against Women and 'Crimes of Honour'. Edited by Lynn Welchman and Sara Hossain. London: Zed Books, pp. xi-xiv.

Dustin, Moira, and Anne Phillips. 2008. Whose agenda Is It? Abuses of women and abuses of 'culture in Britain. Ethnicities 8: 405-24. [CrossRef]

Eckstein, Jessica J. 2011. Reasons for Staying in Intimately Violent Relationships: Comparisons of Men and Women and Messages Communicated to Self and Others. Journal of Family Violence 26: 21-30. [CrossRef]

Gill, Aisha K. 2003. Domestic Violence-Edited. Community Care 1465: 42.

Gill, Aisha K. 2004. Voicing the Silent Fear: South Asian Women's Experiences of Domestic Violence. The Howard Journal 43: 465-83. [CrossRef]

Gill, Aisha K., and Avtar Brah. 2014. Interrogating cultural narratives about 'honour'—Based violence. European Journal of Women's Studies 21: 72-86. [CrossRef]

Gill, Aisha K., and Taher Hamed. 2016. Muslim Women and Forced Marriages in the UK. Journal of Muslim Minority Affairs 36: 540-60. [CrossRef]

Gill, Aisha K., and Karen Harrison. 2019. 'I Am Talking About It Because I Want to Stop It': Child Sexual Abuse and Sexual Violence Against Women in British South Asian Communities. British Journal of Criminology 59: 511-29. [CrossRef]

Gill, Aisha K., and Heather Harvey. 2017. Examining the Impact of Gender on Young People's Views of Forced Marriage in Britain. Feminist Criminology 12: 72-100. [CrossRef]

Kallivayalil, Diya. 2010. Narratives of suffering of South Asian immigrant survivors of domestic violence. Violence against Women 16: 789-811. [CrossRef] [PubMed]

Kelly, Liz. 1988. Surviving Sexual Violence. Cambridge: Polity Press.

Letherby, Gayle. 2003. Feminist Research in Theory and Practice. Buckingham: Open University Press.

Lorde, Audre. 1996. The Audre Lorde Compendium: Essays, Speeches and Journals: The Cancer Journals, Sister Outsider, a Burst of Light. London: Pandora.

Mahmood, Saba. 2005. Politics of Piety: The Islamic Revival and the Feminist Subject. Princeton: Princeton University Press.

Meetoo, Veena, and Heidi Safia Mirza. 2007. "There is nothing 'honourable' about honour killings": Gender, violence and the limits of multiculturalism. Women's Studies International Forum 30: 187-200. [CrossRef]

Mohee, Samia. 2011. Young British South Asian Muslim Women: Identities and Marriage. Ph.D. thesis, University College London, London, UK; p. 364.

Narayan, Uma. 2001. Minds of Their Own: Choices, Autonomy, Cultural Practices, and Other Women'. In A Mind of One's Own: Feminist Essays on Reason and Objectivity. Edited by Louise Antony and Charlotte Witt. Boulder: Taylor \& Francis Group, pp. 418-32.

Oakley, Ann. 2016. Sex, Gender and Society, rev. ed. Abingdon: Routledge.

Pande, Raksha. 2015. 'I arranged my own marriage': arranged marriages and post-colonial feminism. Gender, Place $\mathcal{E}$ Culture 22: 172-87. [CrossRef]

Pande, Raksha. 2016. Becoming modern: British-Indian discourses of arranged marriages. Social E Cultural Geography 17: 380-400. [CrossRef]

Patel, Pragna. 2003a. Shifting Terrains: Old Struggles for New? Edited by Rahila Gupta. London: Zed Books, pp. 234-60.

Patel, Pragna. 2003b. The Tricky Blue Line: Black Women and Policing. Edited by Rahila Gupta. London: Zed Books, pp. 160-87.

Patel, Pragna. 2013. Multi-Faithism and the Gender Question: Implications of Government Policy on the Struggle for Equality and Rights Minority Ethnic Women in the UK. Edited by Yasmin Rehman, Liz Kelly and Hannana Siddiqui. Farnham: Ashgate Publishing Limited, pp. 41-58.

Reynolds, Tracey. 2002. Re-thinking a black feminist standpoint. Ethnic and Racial Studies 25: 591-606. [CrossRef]

Sen, Purna. 2005. 'Crimes of Honour', Value and Meaning. Edited by Lynn Welchman and Sara Hossain. London: Zed Books, pp. 42-63.

Siddiqui, Hannana. 2003. 'It Was Written in Her Kismet': Forced Marriage. Edited by Gupta Rahila. New York: Palgrave, pp. 67-91. 
Siddiqui, Hannana. 2005. 'There is No "Honour" in Domestic Voilence, Only Shame!' Women's Struggles against 'Honour' Crimes in the UK. Edited by Lynn Welchman and Sara Hossain. London: Zed Books, pp. $263-81$.

Siddiqui, Hannana. 2011. 'I Wish I'd Taken Her with Me': The Lives of Black and Minority Ethnic Women Facing Gender-Based Violence. Edited by Tamsin Bradley. London: Zed Books, pp. 169-90.

Siddiqui, Hannana. 2013. 'True Honour: Domestic Violence, Forced Marriage and Honour Crimes in the UK. Edited by Yasmin Rehman, Liz Kelly and Hannana Siddiqui. Farnham: Ashgate Publishing Limited, pp. 169-84.

Siddiqui, Hannana. 2014. Violence against Minority Women: Tackling Domestic Violence, Forced Marriage and 'Honour' Based Violence. Coventry: Centre for the Study of Safety and Well-being Centre for Lifelong Learning University of Warwick.

Siddiqui, Hannana. 2016. What Will It Take to End Honour Based Violence in the UK? OpenDemocracy. Available online: https://www.opendemocracy.net/en/5050/lasting-change-to-end-honour-based-violen/ (accessed on 25 August 2020).

Thiara, Ravi. 2013. 'It's All about Stopping You from Getting on with Your Life': Post-Separation Violence in the Lives of Asian and African-Caribbean Women and Children. Edited by Yasmin Rehman, Liz Kelly and Hannana Siddiqui. Farnham: Ashgate Publishing Limited, pp. 113-26.

Toor, Sunita. 2009. British Asian girls, crime and youth justice. Youth Justice 9: 239-53. [CrossRef]

United Nations. 1948. Universal Declaration of Human Rights. Available online: http://www.ohchr.org/EN/ UDHR/Documents/UDHR_Translations/eng.pdf (accessed on 25 August 2020).

Walby, Sylvia. 1990. Theorizing Patriarchy. Oxford: Basil Blackwell.

Wilson, Amrit. 2006. Dreams, Questions, Struggles: South Asian Women in Britain. London: Pluto Press.

Yuval-Davis, Nira. 2011. The Politics of Belonging: Intersectional Contestations. London: Sage Publications Ltd.

Zaidi, Arshia U., and Muhammad Shuraydi. 2002. Perceptions of arranged marriages by young Pakistani Muslim women living in a Western society. Journal of Comparative Family Studies 33: 495-514. [CrossRef]

(C) 2020 by the authors. Licensee MDPI, Basel, Switzerland. This article is an open access article distributed under the terms and conditions of the Creative Commons Attribution (CC BY) license (http://creativecommons.org/licenses/by/4.0/). 